\title{
Emprego flexível em Portugal ${ }^{1}$
}

ILONA KOUÁCS"

\section{Emprego flexível e suas formas}

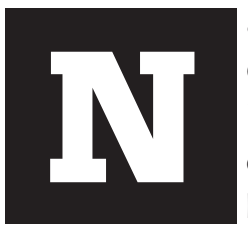

as últimas décadas emergiu uma série de modalidades de emprego que se distancia do modelo de emprego inserido na relação salarial do pós-guerra. Este último compreende um contrato com duração indeterminada, horário de trabalho completo e regulado por contratação colectiva, um determinado local de trabalho, a possibilidade de progressão numa carreira profissional e ainda uma concepção hierárquica e colectiva das relações de trabalho.

É frequente designar as formas emergentes de trabalho (trabalho temporário, auto-emprego, trabalho a tempo parcial, trabalho ao domicílio, teletrabalho, etc.) como atípicas face ao padrão normal do emprego típico dos gloriosos 30 anos pós-guerra. No entanto, a utilização do adjectivo atípico, levanta dúvidas, uma vez que as formas emergentes de emprego, sobretudo nos recentes e actuais recrutamentos passaram a ser cada vez mais "típicas". Embora estas formas particulares de emprego sejam ainda minoritárias se as compararmos com o chamado emprego "normal" com

\footnotetext{
* Professora Catedrática do Departamento de Ciências Sociais. Instituto Superior de Economia e Gestão - Universidade Técnica de Lisboa (Portugal). Endereço eletrônico: ilona@iseg.utl.pt

1 Este artigo insere-se no projecto de investigação em curso, intitulado As formas flexíveis de emprego: riscos e oportunidades, financiado pela Fundação para a Ciência e Tecologia (POCTI № 33042/SOC/2000), bem como no projecto de cooperação "Transformações do Trabalho e do Emprego no Contexto da Reestruturação Económica" no âmbito do Convênio GRICES/CAPES.
} 
contrato de duração indeterminada, contudo, actualmente, elas constituem uma via de acesso normal para a integração no mercado de trabalho.

Outros autores utilizam o termo "novas formas de trabalho" ou de emprego. Neste caso, pretende-se marcar a distância que separa as formas emergentes do padrão antigo, tradicional ou obsoleto. Também parece inadequado o adjectivo "novas", porque muitas dessas formas de emprego não são novas, mas significam um retorno a formas bem antigas de trabalho remunerado, tais como o trabalho ao domicílio, o trabalho temporário, o trabalho independente ou o trabalho a tempo parcial.

Rejeitando os adjectivos acima referidos como inadequados, optei pelo adjectivo "flexível" por considerar como principal característica das formas de emprego actualmente em grande difusão (Brewster et al. 1997; Felstead, Jewson, 1999).

O conceito de emprego flexível está presente já em Atkinson (1987). Este autor, através do "modelo da empresa flexível", analisa a diferenciação entre dois grupos de trabalhadores: o núcleo estável dos trabalhadores chave e os trabalhadores periféricos. Tratar-se-ia de grupos relativamente homogéneos. No que se refere ao núcleo duro, o regime de emprego está estruturado de acordo com o "modelo de solidariedade social", caracterizado pelos seguintes aspectos: cooperação entre parceiros sociais no esforço para aumentar a produtividade, repartição dos ganhos de produtividade associando convenções colectivas e disposições sociais, criação de condições sociais e de condições de mercado encorajadoras da reciprocidade no trabalho melhorando as condições de trabalho e a remuneração, instaurando programas de formação, etc. Do ponto de vista económico, está subjacente a ideia de que uma mão-de-obra segura, qualificada e motivada é adaptável às mudanças e constitui um factor de competitividade por permitir uma grande flexibilidade funcional. A experiência profissional deste grupo está submetida à lógica do longo prazo e comprometimento (empenhamento) mútuo. 
No que se refere aos grupos periféricos e externos, o regime de emprego está estruturado de acordo com o modelo de adaptação ao mercado caracterizado pela libertação dos mecanismos de mercado (inclusive do trabalho) para permitir o livre fluxo dos recursos económicos. O emprego instável dos grupos periféricos permite obter a flexibilidade numérica adequada às flutuações da procura.

Partilhamos a ideia praticamente generalizada, entre os estudiosos do emprego, em torno da crise dos modelos de trabalho e de empresa até há pouco dominantes. Esta crise manifesta-se na redução do emprego estável e a tempo integral a favor de uma multiplicidade de formas de trabalho remunerado cujo denominador comum é a flexibilidade em termos contratuais, de tempo de trabalho, de espaço e de estatutos. Essa é a razão da pertinência do termo formas flexíveis de emprego. No entanto, em vez de opor dois grupos (o núcleo e a periferia) com base na dualização do mercado de trabalho, como faz Atkinson, sublinho a tendência para a crescente diferenciação e heterogeneidade das situações de trabalho e formas de emprego. A difusão de empregos flexíveis insere-se no movimento de reestruturação do processo produtivo e da flexibilização do mercado de trabalho levando à desagregação e dispersão da realização do trabalho, à fragmentação da sua organização.

Numa economia mundializada, com a predominância da lógica financeira e da rendibilidade a curto prazo, existe uma pressão incessante para a máxima flexibilização do factor de trabalho. Os empregadores pretendem uma força de trabalho que responda rapidamente, com facilidade e a baixo custo, aos requisitos e às variações do mercado (Grupo de Lisboa, 1994). A empresa idealizada é a empresa magra ou a "empresa flexível" (Atkinson, 1987) que, de acordo com estratégias diferenciadas, combina diferentes regimes de emprego dentro de si mesma, com vista a obter tanto flexibilidade funcional como flexibilidade quantitativa. Estudos empíricos recentemente realizados a nível da UE mostram que, apesar das diferenças entre os países quanto às formas concretas, o emprego flexível tem vindo a au- 
mentar em toda a Europa (CE, 1998; Brewster et al., 1997). Este aumento é facilitado pela debilidade das forças sindicais e pelo desequilíbrio nas relações capital-trabalho. A difusão de formas de emprego flexíveis pode implicar um forte crescimento de uma força de trabalho fluída que pode ser contratada, despedida, externalizada, de acordo com as necessidades de adaptação ao mercado por parte das empresas (Castells, 1998; Kovács, 2003). Uma parte substancial das formas flexíveis de emprego é precária. A precariedade refere ao trabalho mal pago, pouco reconhecido e que provoca um sentimento de inutilidade, refere ainda à instabilidade do emprego, à ameaça do desemprego, à restrição dos direitos sociais e também à falta de perspectivas de evolução profissional. A difusão das formas precárias está ligada à procura da flexibilização quantitativa e à redução de custos do trabalho através do recurso a vínculos contratuais instáveis e através da substituição de contratos de trabalho por contratos comerciais. ${ }^{2}$

Há uma grande controvérsia em torno das formas flexíveis de emprego. Para uns (Handy, 1984; Bridges, 1994) elas são manifestações do afastamento da sociedade centrada no trabalho assalariado, pautado pela estabilidade e pela previsibilidade dos percursos profissionais. Estas formas inscrevem-se na era da flexibilidade ou da economia flexível que abarca entre outras dimensões - a flexibilidade de emprego, a multiplicidade de opções e oportunidades, o apogeu da afirmação do indivíduo e da sua liberdade. Numa perspectiva crítica, essas formas de emprego são, ao invés, sinais de um retrocesso social e acarretam consequências negativas do ponto de vista da coesão social. (Castel, 1995; Castillo, 1998; Gorz, 1997; Rifkin, 1995). Em meu entender, as formas flexíveis de emprego são ambíguas; tanto implicam riscos, como comportam oportunidades; tanto podem trazer vantagens como desvantagens para os indivíduos nelas envolvidos e para a sociedade em geral. 


\section{A difusão de formas flexíveis de emprego em Portugal}

Portugal costuma ser referido como um país cujo mercado de trabaIho é muito regulado e, por conseguinte, muito rígido. No entanto, a flexibilização da força de trabalho avança, como aliás, nos outros países da União Europeia, independentemente do grau de regulação do mercado de trabalho. De acordo com uma sondagem referente a uma amostra representativa da população portuguesa em 1999, cerca de 3/4 dos empregados tinham contrato de trabalho, $17,7 \%$ não tinham, sobretudo na agricultura/pescas (58,7\%) e no comércio (60\%); mais de metade $(55,1 \%)$ tinham contrato sem termo, 20\% contrato a termo e $20 \%$ contrato de prestação de serviços. Estes dados diferem bastante dos dados do Instituo Nacional de Estatística (INE): em 1999 80,4\% do emprego era com contrato sem termo, 13,8\% com termo, 1,5\% de contrato de prestação de serviços e 4,4\% outro tipo de contrato. Um inquérito feito em 1997 indicou os seguintes dados: emprego sem qualquer contrato $21,5 \%$, com contrato com duração indeterminada $67,5 \%$ e com contrato a termo certo 11,5\% (Cabral, 1998.)

Um dos principais problemas é conhecer com exactidão a extensão e a evolução das diversas formas de emprego flexível, bem como saber quais os grupos sociais mais atingidos. Em diversos estudos (Vaz, 1997; Moniz, Kovács, 1997; Rosa, 2000; Santana, Centeno, 2000; Cerdeira, 2000) realizados, transparece a dificuldade de obter dados estatísticos adequados. Efectivamente, a partir das fontes estatísticas nacionais tornase extremamente difícil proceder a um estudo quantitativo rigoroso, não só devido à dispersão dos dados por múltiplas fontes, mas também porque são variadas as amostras, porque são distintos os critérios metodológicos e os métodos de recolha e tratamento (por vezes, mesmo no âmbito das mesmas fontes de informação). Deste modo, confrontamo-nos com valores diferentes quando analisamos as modalidades de emprego, consoante as fontes de origem. 
Entre as diversas formas flexíveis de emprego podem ser destacadas as mais difundidas, tais como o trabalho com contrato de duração determinada, o trabalho temporário, o trabalho independente e o trabalho a tempo parcial. ${ }^{3}$

\subsection{Os contratos de duração determinada e o trabalho temporário}

Os contratos a termo comportam uma dimensão temporal fixa, isto é, têm os seus limites de início e fim bem definidos. O Código do Trabalho que entrou recentemente em vigor, permite que este tipo de contratos seja renovado três vezes e até ao limite de seis anos. ${ }^{4}$ Até há alguns anos atrás, o recurso a contratos de duração determinada funcionava como uma fase de experimentação, uma espécie de processo de "pré-recrutamento" de trabalhadores efectivos, Hoje este tipo de contrato deixou de significar o acesso a um emprego estável; resulta sim, muitas vezes, numa nova situação precária. Inicialmente este tipo de relação contratual cobria maioritariamente mão-de-obra pouco qualificada. Contudo, indicadores recentes mostram que o nível das qualificações dos trabalhadores com contrato de duração determinada tende a aumentar.

O trabalho temporário assemelha-se ao contrato de duração determinada. Uma das diferenças essenciais reside na existência de uma relação triangular entre empresa de trabalho temporário (ETT) como empregador, a empresa utilizadora e o trabalhador. O trabalhador trabalha na empresa utilizadora, mas tem vínculo contratual com a ETT. A duração do contrato pode ser a termo certo (3, 6 ou 12 meses renovável até máximo de 2 anos) ou termo incerto. Ainda existe a modalidade de contrato renovável semanalmente até ao máximo de 12 meses. Por vezes, as empresas utilizadoras estabelecem com as empresas de trabalho temporário uma relação de fidelidade. Elas impõem às empresas de trabalho temporário a escolha de pes- 
soas com perfis bem definidas, pessoas essas que já foram "testadas" a nível de qualificações profissionais anteriormente.

Como o gráfico seguinte indica, a proporção do trabalho com contratos de duração temporária em Portugal (21,8\%) e, sobretudo em Espanha $(31,2 \%)$, é bastante superior à da média da União Europeia $(13,1 \%)$ :

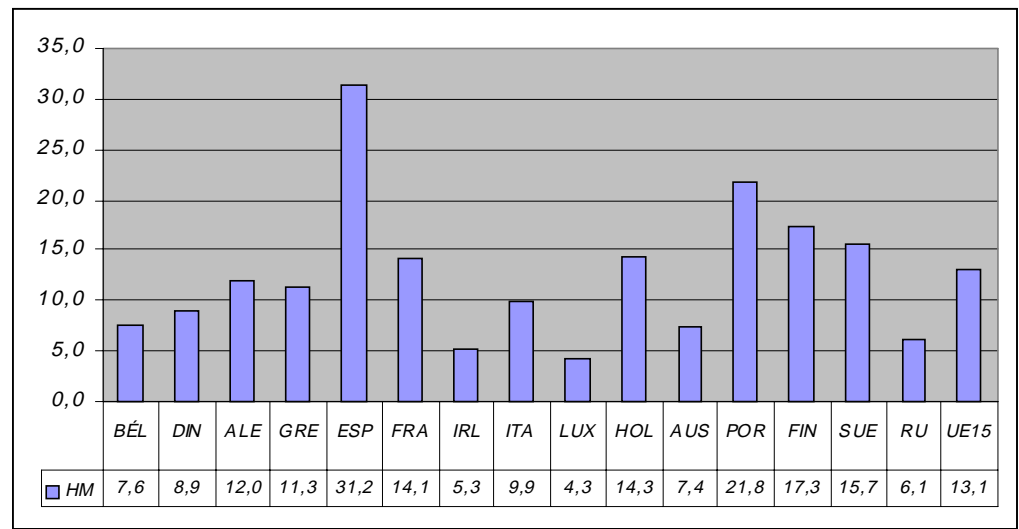

Gráfico 1: Trabalho temporário ${ }^{5}$ na Europa - 2002 (\%)

Fonte: Eurostat, Labour Force Survey 2002

O trabalho temporário atinge sobretudo jovens, mulheres e indivíduos portadores de baixos níveis de escolaridade e com poucas (ou mesmo sem) qualificações.

O crescimento do trabalho temporário em Portugal supera muito o crescimento verificado na União Europeia, como se vê no gráfico seguinte: 


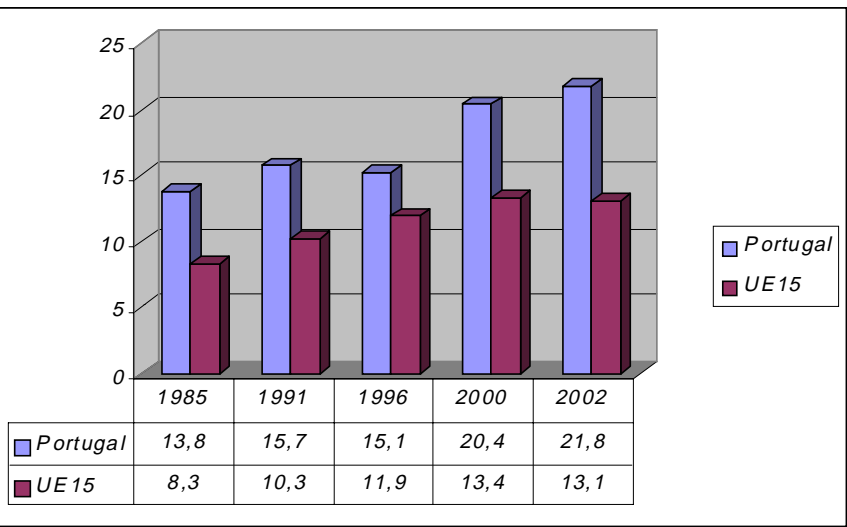

Gráfico 2: Evolução do emprego temporário na União Europeia e em Portugal (\%)

Fonte: European Commission, Employment in Europe 2000; Eurostat, Labour Force Survey 2002

\subsection{Trabalho independente ou auto-emprego}

O trabalho independente é realizado pelo indivíduo que exerce a sua actividade por conta própria. Trata-se de um trabalhador que é simultaneamente um empresário. A nível das estatísticas em Portugal (INE), o trabalho por conta própria, sem recorrer a assalariados, constitui uma modalidade de situação na profissão. Mas, por exemplo, a OCDE junta na mesma categoria do trabalho independente patrões e pessoas que trabaIham por conta própria, por sua vez, a Eurostat considera trabalhador independente aquele que possui uma empresa, exploração agrícola ou profissão liberal e nela trabalha com o objectivo de lucro. Assim, trata-se de uma forma de emprego não só antiga, mas também muito complexa e 
diversificada. A diversidade das situações do trabalho independente são notórias entre os vários países. ${ }^{6}$

O trabalho independente cresce no sector de serviços, enquanto decresce no sector agrícola. O trabalho independente resulta de duas estratégias opostas: uma que decorre da desvalorização do trabalho, na medida em que serve essencialmente para transferir a gestão do trabalho e os riscos para os trabalhadores que têm pouca qualificação ou se encontram numa situação de vinculação contratual precária; outra que valoriza o trabalho, visto que o recurso ao trabalho independente implica grandes capacidades de inovação e adaptação de trabalhadores autónomos com altos níveis de qualificações.

Os dados estatísticos sobre trabalho independente escondem, na maior parte das vezes, situações de trabalho muito heterogéneas desde o trabaIho dependente precário até o trabalho altamente qualificado dos profissionais independentes. Nela se encontram aqueles que deliberadamente optam por serem independentes, no sentido literal do termo, e também os chamados falsos independentes que são forçados a aceitar essa situação num contexto de precariedade laboral. Ao longo dos anos, o trabalho independente nem sempre beneficiou do mesmo estatuto. Depois de uma época de desvalorização, conheceu a partir dos anos 70/80 um novo impulso. ${ }^{7}$ Várias opiniões sustentam que este desenvolvimento se fica a dever não só às exigências de flexibilidade, mas a um conjunto de políticas que

6 Assim, o direito alemão distingue três categorias de trabalho independente. Duas reportam-se a empresários que podem trabalhar em função de um contrato de empresa ou de um contrato de serviços. A terceira categoria é semelhante à dos trabalhadores assalariados, na medida em que o trabalhador independente depende economicamente do empregador. Todas estas categorias são juridicamente inscritas na figura do trabalhador independente, mas a lei aplica-lhes certas disposições do direito do trabalho em termos de convenções colectivas, férias e contenciosos de trabalho. A dependência económica traduzse no facto de o trabalhador independente trabalha só e mais de metade dos seus rendimentos provêm de um empregador. Diferentemente da realidade alemã, os trabalhadores independentes na Itália não estão sujeitos a um regime de protecção social. Nos Países Baixos o projecto de lei em curso prevê um regime de protecção social para os trabalhadores independentes equivalente aos trabalhadores assalariados. Em Espanha, prevê-se a extensão do direito do trabalho em regime parcial para os trabalhadores independentes.

7 Particularmente significativo nos países mais afectados pelo desemprego. Como por exemplo: Bélgica, Espanha, Irlanda ou a Alemanha. 
estimulam a criação do próprio emprego (muitas vezes, o caso das microempresas). ${ }^{8}$ O gráfico seguinte apresenta o grau de difusão do auto-emprego na União Europeia:

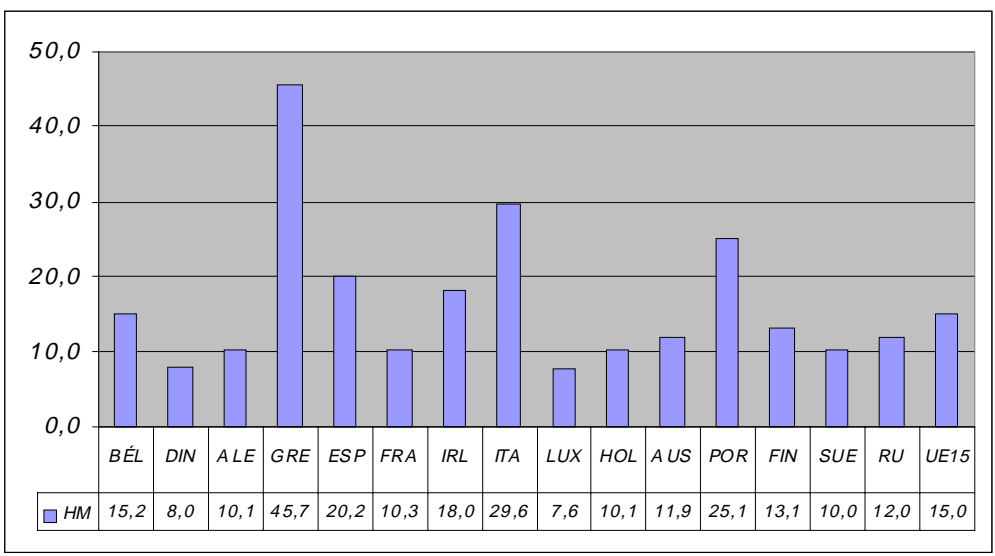

Gráfico 3: Auto-emprego na União Europeia - 2002 (\% do total de empregados entre os 15 e os 59 anos)

Fonte: Eurostat, Labour Force Survey 2002

Os dados estatísticos indicam uma forte proporção de auto-emprego, sobretudo nos países da Europa do Sul, como Grécia (45,7\%) Itália (29,6\%), Portugal (25,1\%) e Espanha (20,2\%), que é bem superior à média europeia $(15,0 \%) .{ }^{9}$ No que se refere às tendências de evolução, há uma certa estagnação a nível europeu e uma ligeira redução em Portugal (ainda que com alguma recuperação mais recentemente), como se pode ver no gráfico seguinte:

8 São igualmente feitas referências a outras actividades: desde as mais tradicionais formas de doação de trabalho para realizar no domicílio (escritas, por exemplo), às mais recentes (teletrabalho), passando pela recuperação de saberes e fazeres domésticos às formas renovadas de entreajuda social com valor económico local. Finalmente, o surgimento de novos modelos de descentralização e articulação de actividades empresariais (subcontratação e o franchising).

9 Dados OCDE e Eurostat. 


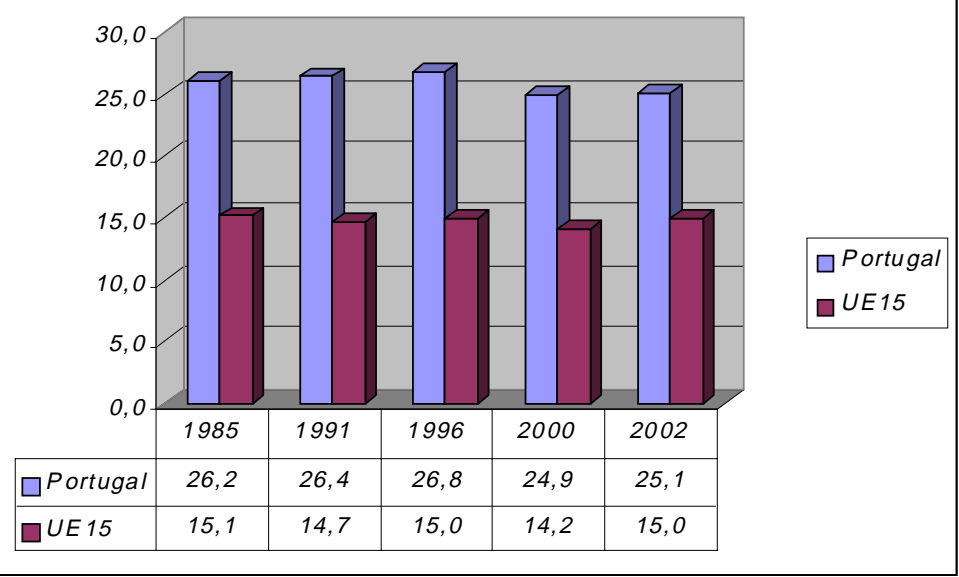

Gráfico 4: Evolução do auto-emprego na União Europeia e em Portugal (\%) Fonte: European Commission, Employment in Europe 2000; Eurostat, Labour Force Survey 2002

Os dados do Instituto Nacional de Estatística, permitem separar os trabalhadores por conta própria sem pessoal ao serviço dos trabalhadores por conta própria com pessoal ao serviço. Assim, em Portugal em 2000 $17,3 \%$ do emprego pertencia a modalidade de trabalhadores por conta própria sem pessoal ao serviço e 5,9\% a modalidade os trabalhadores por conta própria com pessoal ao serviço. Como se depreende, de modo semelhante às outras formas flexíveis de emprego, estamos na presença de uma categoria heterogénea. Uma parte destes trabalhadores carecem independência e na realidade não são autónomos mas trabalham por conta de outrem, ganhando menos, vivendo a pressão do risco, sem ou com fraca protecção sindical, sendo excluídos da aplicação de certas leis e mais vulneráveis. É neste sentido que André Gorz (1997) desmistifica a figura pós-fordista do 
trabalhador independente quando considera que, na maior parte das vezes, este trabalhador trabalha a preços e em condições que os assalariados julgam inaceitáveis.

\subsection{Trabalho a tempo parcial}

Nos casos anteriores - contratos de duração determinada e contratos temporários - a variável de ajustamento era o próprio emprego; no caso do trabalho a tempo parcial, a variável de ajustamento reside no tempo de trabalho. O conjunto de situações que esta forma de emprego pode atingir é enorme: horas por dia, mês, semana, etc. A situação dos trabalhadores a tempo parcial diverge consideravelmente segundo os sectores de actividade. Na administração, banca e seguros, o trabalho a tempo parcial é objecto de negociação e de uma forma geral resulta de uma escolha explícita por parte dos trabalhadores. Pelo contrário, noutros sectores, como é o caso da restauração, do comércio a retalho, entre outros, o trabalho a tempo parcial quase se instituiu como a norma, a realidade é bem diferente.

Nas duas últimas décadas, assistiu-se a um aumento generalizado do trabalho a tempo parcial nos países desenvolvidos. Não deixa de ser curioso verificar que, são os próprios governos a encorajar/facilitar esta forma de emprego, numa tentativa de diminuir, as elevadas taxas de desemprego. Mas, ao mesmo tempo, vários estudos permitem concluir com alguma segurança que uma parte substancial dos trabalhadores com um horário inferior ao normal gostariam de ter um trabalho com um horário completo. Assim, esta situação parece aproximar-se do subemprego numa escala macroeconómica e macro-social. O trabalho a tempo parcial está mais difundido nos países nórdicos e muito menos nos países do sul da Europa, nomeadamente em Portugal, como se pode ver no gráfico seguinte: 


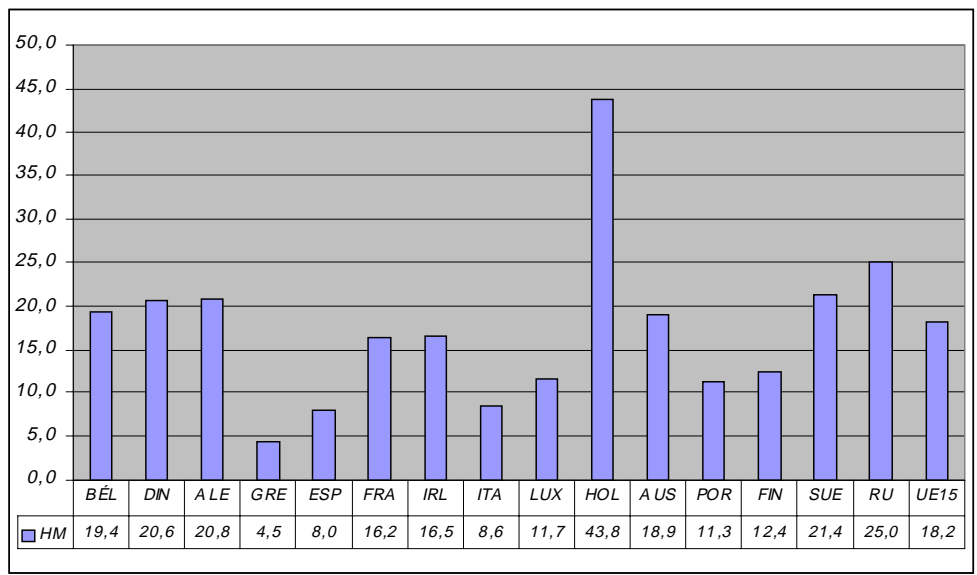

Gráfico 5: A difusão do emprego a tempo parcial na União Europeia - 2002 (\% do total de empregados)

Fonte: Eurostat, Labour Force Survey 2002

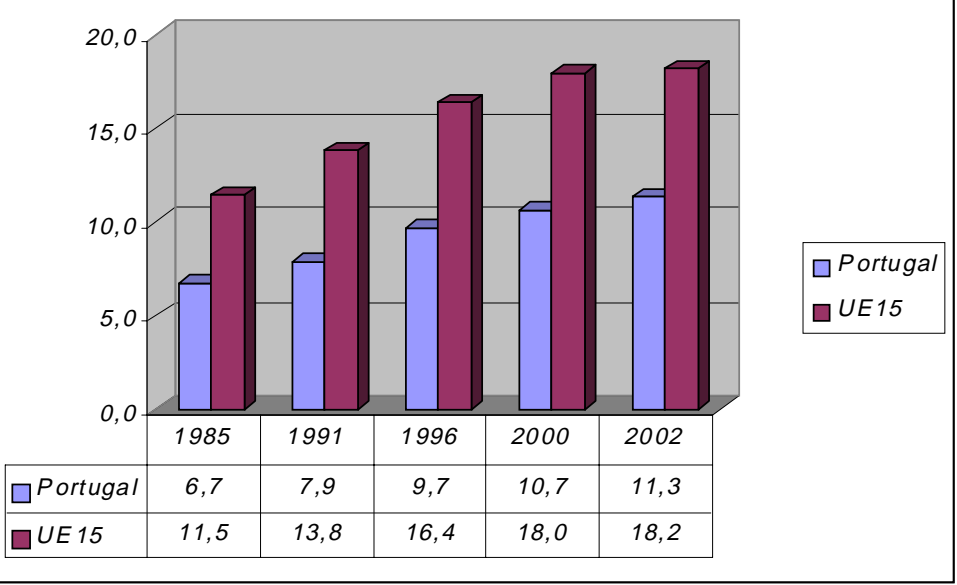

Gráfico 6: Evolução do trabalho a tempo parcial na União Europeia e em Portugal (\%)

Fonte: European Commission, Employment in Europe 2000; Eurostat, Labour Force Survey 
Em Portugal a proporção daqueles que trabalham a tempo parcial por motivos involuntários é muito superior $(45,5 \%)$ a média europeia (18\%). A tendência a nível europeu tem sido um rápido crescimento, mas em Portugal verifica-se um crescimento mais lento, como indica o gráfico 6 :

Esta forma de é mais divulgada no sector dos serviços e prevê-se seu maior crescimento. Uma das intenções do Governo português, aliás expressas no Plano Nacional de Emprego, é precisamente estimular o trabaIho a tempo parcial, assim como todas as modalidades flexíveis de trabalho. É de sublinhar ainda a sobre-representação das mulheres nesta modalidade, em toda a Europa, se bem que o número de homens a trabalhar nesta modalidade também tenha aumentado. Trata-se ainda de uma modalidade com forte representatividade junto dos jovens (menos de 25 anos) e sobretudo junto daqueles que têm mais de 55 anos de idade a nível da União Europeia. Em Portugal esta modalidade tem pouca representação nas camadas mais jovens e tem um forte peso (58\%) entre os indivíduos com mais de 65 anos.

Nos países com elevadas taxas de desemprego, foram tomadas medidas para facilitar a difusão desta modalidade de emprego. É de referir a experiência holandesa. (Visser, Hemerijck, 1997). Os contratos de trabalho a tempo parcial neste país passaram de 22\% em 1983 para 38\% em 1998 no caso das mulheres e de $6,8 \%$ para $16,1 \%$ no caso dos homens. Os contratos de trabalho temporário também aumentaram no mesmo período: de $5,8 \%$ para $10,9 \%$. Como no mesmo período a taxa de desemprego desceu de $11,2 \%$ para $5 \%$ e a taxa de participação das mulheres no mercado de trabalho aumentou de 34\% em 1983 para 55\% em 1996. Com base nestes dados, fala-se do milagre holandês. De facto, as políticas implementadas neste país contribuíram significativamente para a redução do desemprego e para o aumento da taxa de actividade. É de ressaltar que para estas formas flexíveis de emprego foram dados os mesmos direitos sociais usufruídos pelo emprego estável. Todavia, a criação dos empregos flexíveis, sobretudo, do emprego temporário e do trabalho a tempo parcial 
incidiu no sector dos serviços com baixa qualificação e com baixo nível de produtividade. Acresce ainda que estes empregos foram ocupados, principalmente por mulheres e jovens. Das medidas tomadas neste país transparecem três preocupações básicas. Tornar as empresas mais lucrativas, remover os incentivos para ficar fora do mercado de trabalho e prevenir a precarização dos novos empregos criados. Parece, todavia que os custos da flexibilização do mercado de trabalho necessária para a competitividade das empresas foram transferidas para as mulheres e jovens. As formas flexíveis de emprego, apesar do esforço feito para a sua normalização, significam uma situação débil do ponto de vista do rendimento e da acessibilidade à formação profissional e, por conseguinte, da melhoria da empregabilidade.

\section{A diversidade dos empregos flexíveis}

\subsection{Algumas considerações metodológicas}

Dados os condicionalismos acima apontados, as estatísticas permitem apenas uma análise limitada das transformações ao nível do emprego. Mas uma abordagem quantitativa séria depende do desenvolvimento e aperfeiçoamento do aparelho estatístico. Todavia, o estudo das modalidades flexíveis de emprego exige também uma abordagem qualitativa. Face aos discursos ideológicos sobre as formas flexíveis de emprego, importa conhecer como os trabalhadores vivem e sentem essa flexibilidade, em que medida as formas flexíveis de emprego vão ou não ao encontro das suas expectativas e em que medida permitem a sua integração social e cultural nos grupos de pertença.

Porém, a investigação enfrenta grandes dificuldades. Os estudos realizados, já mencionados, sobre as mudanças no emprego indicam que não 
obstante as sucessivas tentativas, as empresas ligadas aos sectores mais susceptíveis à utilização de formas instáveis de emprego, não aceitam colaborar $^{10}$, ou então de modo muito limitado (Cerdeira, 2000). Mesmo quando autorizam a realização de entrevistas, o acesso limita-se aos gestores, especialmente aos dos recursos humanos e aos trabalhadores com contrato de duração indeterminada. Já é mais difícil chegar aos que têm contratos com duração determinada. E é praticamente impossível contactar, por via de empresa, os trabalhadores que se encontram em outras formas cobertas pela legislação laboral, tais como o trabalho temporário, o trabalho no domicílio e prestação de serviços por trabalhadores por conta própria. As situações de ilegalidade também são abundantes, mas praticamente inacessíveis. Os estudos até então realizados com muito esforço não conseguiram ou muito pouco tornar visíveis as situações reais de trabalho daqueles que se encontram ligados a modalidades flexíveis de emprego.

Como vimos, as estatísticas indicam que em Portugal as situações de trabalho por conta própria, contrato a curto prazo e trabalho temporário, (com particular incidência em certos grupos, tais como mulheres, jovens, trabalhadores com baixo nível de escolaridade) são muito difundidas. No entanto, quando se contacta as empresas, fica-se com a ideia que a utilização de formas flexíveis de emprego é muito rara. No discurso dos gestores/ empresários, as formas instáveis de emprego são pouco utilizadas não existindo além disso grandes diferenças entre a situação dos trabalhadores com vínculos precários e efectivos. Devido à ocultação das situações de trabalho pelas empresas, torna-se necessária descentrar o estudo do trabalho das empresas e recorrer a outras entidades, nomeadamente aos Centros de Emprego, aos Sindicatos ou ainda às empresas de trabalho temporário e, sobretudo, contactar directamente os trabalhadores.

10 A elaboração de um estudo sobre a precariedade do emprego encontrou muitas dificuldades, ao longo de 4 meses foram estabelecidos contactos repetidas vezes com 80 empresas e apenas 7 aceitaram a colaboração para a realização do estudo. Cf.: Teresa Rosa (coord.), Trabalho precário - Perspectivas de Superação, Observatório de Emprego e Formação Profissional, Lisboa 2000. 
As formas instáveis de emprego escapam às estatísticas por serem muito variadas e dentro de cada tipo as situações estarem muito heterogéneas e, por conseguinte, difíceis de identificar. O inquérito constitui um instrumento útil para identificar os grupos mais atingidos pelas diversas formas. Mas também importa compreender as trajectórias diversas e os processos que levam certas pessoas a acumular vantagens e as outras desvantagens. Interessa saber em que medida e em que condições as situações instáveis de emprego e/ou ocupações temporárias constituem ponte para uma situação profissional mais estável ou, se, pelo contrário, são uma armadilha que amarra os trabalhadores a uma espiral de precariedade? Importa também indagar a existência de um processo cumulativo de experiências no mercado de trabalho que acentua a vulnerabilidade dos grupos mais frágeis. Com vista a estes objectivos foi aplicado um questionário e foram feitas entrevistas centradas nas trajectórias profissionais com base numa amostra intencional construída de acordo com os objectivos do estudo. A selecção das empresas e dos indivíduos tinha por base as características pertinentes para o estudo para garantir a representatividade da problemática e não a representatividade estatística.

\subsection{Tipos de empregos flexíveis}

A difusão dos empregos flexíveis leva não a uma simples dualização entre trabalhadores permanentes bem pagos do núcleo duro e os trabalhadores periféricos com emprego incerto e mal pago, mas a uma segmentação dos recursos humanos nas empresas. A tipologia que se segue apresenta a diversidade de situações face ao emprego e às perspectivas de empregabilidade. Esta tipologia foi elaborada de acordo com as situações face ao emprego, cujas variáveis centrais são os níveis de formação/qualificação exigidos e o grau de estabilidade/flexibilidade do emprego. 
A figura seguinte apresenta essas situações-tipo:

\begin{tabular}{|c|c|c|}
\hline+ & Situação 3: Flexibilidade qualificante & Situação 4: Estabilidade profissional \\
\hline & $\begin{array}{l}\text { - situação por opção (escolhida); } \\
\text { - trabalho altam ente qualificado } \\
\text { (profissional), permitindo e exigindo } \\
\text { aprendizagem contín ua; } \\
\text { - posição e capacidade de } \\
\text { negociação dos individuos com o } \\
\text { empregador; } \\
\text { - forte mobilidade profissional } \\
\text { no mercado de trabalho externo } \\
\text { (entre empresas); } \\
\text { - perspectivas profissionais: } \\
\text { actividade profissional intensa e } \\
\text { qualificante, ligada a uma serie de } \\
\text { empresas sem vínculos estáveis. }\end{array}$ & $\begin{array}{l}\text { - trabalho variado e interessante, } \\
\text { oferecendo possibilidades de } \\
\text { aprendizagem no trabalho; } \\
\text { - forte interesse por parte da } \\
\text { empresa em investir na formação; } \\
\text { - posição e capacidade de } \\
\text { negociação dos individuos e dos } \\
\text { grupos com o empregador sobre } \\
\text { salários e condiçóes de trabalho; } \\
\text { - forte possibilidade de mobilidade } \\
\text { horizontal y/o ascendente no } \\
\text { mercado de trabalho interno } \\
\text { yexterno. }\end{array}$ \\
\hline Calificação & $\begin{array}{c}\text { Situação l: Flexibilidade } \\
\text { precariezante }\end{array}$ & Situação 2: Estabilidade am eaçada \\
\hline & $\begin{array}{l}\text { A) Flexibilidade precária transitória- } \\
\text { jovens com niveis de educação } \\
\text { elevados/médios; } \\
\text { - trabalho pobre em conteúdo } \\
\text { lim itando fortem ente o uso das } \\
\text { competências e a aprendizagem no } \\
\text { trabalho; } \\
\text { - falta de capacidade de negociacão } \\
\text { com o empregador; } \\
\text { - procura de uma situação } \\
\text { profissional melhor } \\
\text { B) Flexibilidade precária estável- } \\
\text { forte mobilidade lateral, sobre todo } \\
\text { o mercado de trabalho externo; } \\
\text { - perspectivas profissionais: forte } \\
\text { probabilidade de um percurso } \\
\text { marcado pela precariedade e ameaça } \\
\text { de desemprego }\end{array}$ & $\begin{array}{l}\text { - trabalho pobre em conteúdo } \\
\text { limitando fortem ente a } \\
\text { aprendizagem no trabalho; } \\
\text { - posiça de negociação individual } \\
\text { frágil, com eventual capacidade de } \\
\text { negociação sindical com } \\
\text { o empregador; } \\
\text { - mobilidade lateral no mercado de } \\
\text { trabalho interno, mobilidade } \\
\text { ascendente lim itada; } \\
\text { - perspectivas profissionais: melhoria } \\
\text { da qualificação para um segmento } \\
\text { pequeno; para a maioria, falta de } \\
\text { perspectivas e ameaça de } \\
\text { precariedade e de desemprego. }\end{array}$ \\
\hline - & Estabilidade de em prego & + \\
\hline
\end{tabular}

Figura 1: Situação face ao emprego e as perspectivas de empregabilidade Fonte: Kovács, Ilona, 2002, p. 87 
A flexibilidade do emprego pode ser precária transitória (situação 1 A), precária estável (situação 1 B), ou pode ser qualificante (situação 3). A situação 1B refere a uma trajectória marcada pela precariedade e ameaça de desemprego. A estabilidade do emprego pode ser duradoura (situação 4) ou ameaçada (situação 2). Devido à grande diferença no conteúdo de trabalho e às limitações da formação daqueles que se encontram numa situação fragilizada, é difícil a mobilidade ascendente para as situações 3 e 4 daqueles que se encontram nas situações 1B e 2. Há indícios de uma forte tendência para trajectórias precarizantes ou de exclusão: o fim do emprego com duração limitada constitui uma das principais razões da procura de um novo emprego por parte dos desempregados para além dos despedimentos individuais e colectivos. Como é possível melhorar a situação dos grupos fragilizados e criar condições para que haja mobilidade ascendente? Por outras palavras, como contrariar a tendência para trajectórias de emprego precárias e de exclusão a favor de trajectórias de integração? Aqueles que se encontram nas situações 1B e 2 necessitariam de formação para melhorar a sua empregabilidade. Estes grupos estão em desvantagem em relação àqueles que se encontram nas situações 3 e 4 quanto às possibilidades reais e motivação para a melhoria das suas qualificações pela formação.

As empresas tendem a investir cada vez mais na formação daqueles que se encontram na situação 4, reconhecendo que a melhoria das competências destes trabalhadores chave é condição da melhoria da sua competitividade. Estão interessadas em que este investimento retorne pela melhor performance dos recursos humanos. Por essa razão as empresas suportam os encargos mais elevados relacionados com estes grupos, em termos de estabilidade de emprego e rendimento.

No que se refere aos trabalhadores inseridos na situação 1, do ponto de vista da empresa, o seu principal interesse está na possibilidade de adaptar o número de empregos e horas de trabalho às flutuações do mercado (flexibilidade quantitativa). Aqui estão incluídas as situações referentes ao 
emprego com contratos a termo e tempo parcial involuntários (De Grip, Hoevenberg, Willems, 1997), trabalho temporário ligado às Empresas de Trabalho Temporário, falso trabalho independente, entre outras. Este tipo de situação tende a ganhar terreno em detrimento das situações de emprego estáveis (2 e 4).

Na situação 2 encontram-se, sobretudo, os trabalhadores pouco ou semi-qualificados com elevada antiguidade tendo um vínculo contratual de duração indeterminada. Porém, estes grupos em qualquer momento podem passar para a situação de emprego precário ou para o desemprego. A estabilidade do seu emprego é apenas aparente.

Cada vez mais as novas contratações tendem a ser feitas sob a forma de empregos instáveis. Os jovens, mesmo com um nível de escolaridade relativamente elevado na sua maioria, iniciam a sua inserção no mercado de trabalho com este tipo de situação precarizante transitória (1A), com a expectativa de conseguir um emprego estável com perspectiva de carreira. Apesar de a inserção precária dos jovens ser cada vez mais considerada como a forma normal, estes, segundo diversas sondagens realizadas, valorizam fortemente a estabilidade do emprego. (Cabral, 2000; Kovács, 2000). A passagem frequente de um emprego provisório subqualificado para outro por parte dos jovens pode levar a trajectórias profissionais marcadas pela precariedade (1B) e ameaça de desemprego.

Em vez da mobilidade entre as situações de emprego, verifica-se uma tendência para a reprodução do estatuto de emprego. Por outras palavras, o acesso aos bons empregos é muito reduzido, e aqueles que têm empregos com baixo nível de qualidade, têm muito pouca probabilidade de obter empregos com melhor qualidade. No inquérito referido, as dimensões da qualidade do emprego que foram tomadas em consideração referem-se à segurança do emprego, ao acesso à formação e ao desenvolvimento da carreira e ainda ao salário por hora. A mobilidade encontrada entre os quatro tipos de empregos foi a seguinte: 
Quadro 1: Dinâmicas da qualidade do emprego (taxas de mobilidade em \%

\begin{tabular}{|c|c|c|c|c|c|}
\hline $\begin{array}{l}\text { Situação perante o } \\
\text { emprego em } 1996\end{array}$ & & & $\begin{array}{c}\text { Situação no } \\
\text { emprego em } 1995\end{array}$ & & \\
\hline & $\begin{array}{l}\text { Emprego } \\
\text { de boa } \\
\text { qualidade }\end{array}$ & $\begin{array}{l}\text { Emprego } \\
\text { de razoável } \\
\text { qualidade }\end{array}$ & $\begin{array}{c}\text { Baixo } \\
\text { salário baixa } \\
\text { productividade }\end{array}$ & $\begin{array}{l}\text { Emprego } \\
\text { "beco sem } \\
\text { saída" }\end{array}$ & Desemprego \\
\hline $\begin{array}{c}\text { Emprego de boa } \\
\text { qualidade }\end{array}$ & 75,5 & 17,9 & 14,3 & 4,6 & 1,9 \\
\hline $\begin{array}{c}\text { Emprego de } \\
\text { razoável qualidade }\end{array}$ & 16,4 & 67,9 & 18,6 & 19,8 & 4,8 \\
\hline $\begin{array}{c}\text { Baixo salário/baixa } \\
\text { produtividade }\end{array}$ & 4,1 & 6,2 & 52,2 & 13.7 & 6,5 \\
\hline $\begin{array}{c}\text { Emprego } \\
\text { "beco sem saida" }\end{array}$ & 0,6 & 2,8 & 4,8 & 36,3 & 7,8 \\
\hline Desemprego & 1,1 & 2,3 & 4,4 & 14,9 & 57,9 \\
\hline
\end{tabular}

Fonte: ECHP - European Community Household Panel, (1995-96) in EC. Employment in Europe, 2000

Os dados estatísticos do INE, indicam igualmente a tendência para a reprodução das situações contratuais, como indica o quadro seguinte:

Quadro 2: Trabalhadores por conta de outrem segundo o tipo de contrato um ano antes, por tipo de contrato actual - $2000(\%)$

\begin{tabular}{|c|c|c|c|c|c|}
\hline \multirow{2}{*}{$\begin{array}{c}\text { Tipo de contarto } \\
\text { em 2000 }\end{array}$} & \multicolumn{5}{|c|}{ Tipo de contrato em 1999 } \\
\cline { 2 - 6 } & $\begin{array}{c}\text { Contrato } \\
\text { sem term o }\end{array}$ & $\begin{array}{c}\text { (ontrato } \\
\text { com termo o } \\
\text { (a prazo) }\end{array}$ & $\begin{array}{c}\text { Contrato de } \\
\text { prestação } \\
\text { de serviços }\end{array}$ & $\begin{array}{c}\text { Trabalho } \\
\text { sazonal s } \\
\text { contrato escrito }\end{array}$ & $\begin{array}{c}\text { Trabalho } \\
\text { pontual ou } \\
\text { ocasional }\end{array}$ \\
\hline Contrato sem termo & 96,0 & 3,4 & 0,2 & 0,2 & 0,2 \\
\hline $\begin{array}{c}\text { Contrato com termo } \\
\text { (a prazo) }\end{array}$ & 19,1 & 76,1 & 1,8 & 1,3 & 1,8 \\
\hline $\begin{array}{c}\text { Contrato de } \\
\text { prestação de serviços }\end{array}$ & 15,6 & 10,0 & 71,4 & $\S$ & $\S$ \\
\hline $\begin{array}{c}\text { Trabalho sazonal s) } \\
\text { contrato escrito }\end{array}$ & 12,1 & 7,6 & 2,5 & 74,4 & 3,1 \\
\hline $\begin{array}{c}\text { Trabalho pontual ou } \\
\text { ocasional }\end{array}$ & 11,0 & $\mathbf{8 , 1}$ & 1,7 & 3,9 & 75,2 \\
\hline
\end{tabular}

Fonte: INE, Inquérito ao Emprego, médias anuais 
Verificámos esta mesma tendência pelo inquérito realizado no âmbito da nosso projecto de investigação, ou seja, os indivíduos que estão com contrato sem termo, já anteriormente se encontravam nessa situação e por sua vez, os indivíduos com contrato através de empresa de trabalho temporário, também estavam já nessa situação nos dois empregos anteriores.

Há um grande desfasamento entre as tendências de evolução do emprego e as expectativas dos trabalhadores. Resultados de diversos estudos realizados em Portugal refutam algumas teses bastante divulgadas, nomeadamente a da perda da importância subjectiva do trabalho e a da adesão às formas flexíveis de emprego. De facto, em Portugal, o trabalho remunerado continua a ser uma referência dominante, não apenas em termos económicos, mas também psicológicos e culturais. De acordo com os resultados de um inquérito internacional (Cabral, 1997; 2000), para 76,1\% dos inquiridos (uma amostra representativa da população portuguesa) o trabalho é a actividade mais importante, $64 \%{ }^{11}$ gostariam de ter um emprego, mesmo sem precisarem do dinheiro ${ }^{12}, 88,8$ \% têm orgulho no seu trabalho e 84 \% na empresa/organização onde trabalha. Predomina a preferência pelo trabalho assalariado estável e a tempo inteiro. ${ }^{13}$

Quadro 3: Valorização subjectiva do trabalho em Portugal

\begin{tabular}{|c|c|}
\hline Importância do trabalho & $\%$ \\
\hline 0 trabalho é a actividade mas importante & 76,1 \\
\hline Gostava de trabalhar sem precisar de dinheiro & 63,2 \\
\hline Estou disposto a trabalhar para ajudar a empresa a ter êxito & 64,6 \\
\hline Tenho orgulho trabalhar na em presa & 84,0 \\
\hline Tenho orgulho no trabalho que faço & 78,8 \\
\hline Preocupação com a perda de emprego & 41,3 \\
\hline Um emprego ideal é a tempo inteiro & 72,5 \\
\hline
\end{tabular}

Fonte: Cabral, 1997

11 No que se refere aos outros países a situação é a seguinte: Espanha: 53,6\%, Alemanha 74,6\%, Suécia 76,9\% e Hungria 62\%. 12 É de notar que é maior a centralidade do trabalho entre as idades compreendidas entro so 18 e 34 anos e entre os mais escolarizados.

$1373,3 \%$ dos inquiridos preferem trabalhar por conta de outrém, 72,5\% preferem o emprego em tempo inteiro. 
O aspecto mais valorizado do emprego é a estabilidade: 76,7\% dos inquiridos consideram este aspecto como muito importante, mais do que outros aspectos. ${ }^{14}$

Quadro 4: Grau de importância dos diversos aspectos do emprego (1 a 5)

\begin{tabular}{|c|c|c|}
\hline Valores do Trabalho & Expectativas & Realização das expectativas \\
\hline Estabilidade do emprego & 4,7 & 3,6 \\
\hline Remuneração elevada & 4,2 & 2,1 \\
\hline Boas oportunidades de promoção & 4,2 & 2,6 \\
\hline U m trabalho interessante & 4,2 & 4,2 \\
\hline U m trabalho com autonomia & 3,7 & 3,9 \\
\hline U m trabalho útil para a sociedade & 4,3 & 4,3 \\
\hline Poder decidir horários/dias de trabalho & 3,3 & - \\
\hline
\end{tabular}

Fonte: Cabral, 2000

A valorização dada ao trabalho e aos seus diversos aspectos indicam que as actuais transformações não vão ao encontro das expectativas e dos valores relacionados com o trabalho dos portugueses. Face à relativa homogeneidade das expectativas, verifica-se uma grande diferenciação em relação ao grau de satisfação segundo a situação no emprego.

Como podemos ver no quadro que se segue, para os trabalhadores com emprego flexível não há nenhuma dimensão com alto nível de satisfação. A maior satisfação verifica-se na relação com os colegas e superiores (nível médio/bom), tempo livre e possibilidade de escolher o horário (nível médio) e condições de trabalho (nível médio). Ressalta ainda o baixo nível

14 No que se refere aos outros aspectos, a proporção dos inquirídos que os considerou muito importante é o seguinte: horário adequado: $16,7 \%$, autonomia: $29.4 \%$, remuneração elevada: $39,8 \%$, oportunidades de promoção: $37,4 \%$, conteúdo do trabalho: $49,2 \%$, ajuda aos outros: $45,8 \%$, utilidade social do trabalho: $48,45 \%$. 
de satisfação com as oportunidades de promoção, com a estabilidade e segurança quanto ao futuro profissional, com a participação nas decisões e com a autonomia no trabalho. Os trabalhadores com emprego estável são mais satisfeitos com os aspectos referentes às relações com os colegas, ao contrato de trabalho e à estabilidade profissional. No entanto, trabalham em excesso, sobretudo os quadros superiores e os técnicos especializados, frequentemente 40-50 horas por semana. Não é por acaso que a sua maior insatisfação diz respeito à falta de tempo livre e à impossibilidade de escolher o horário de trabalho.

Quadro 5: Grau de satisfação com os diversos aspectos do emprego segundo categoria profissional (1 a 5)

\begin{tabular}{|c|c|c|}
\hline Aspectos do emprego & Emprego estável & Emprego flexivel \\
\hline $\begin{array}{l}\text { Relações com colegas, } \\
\text { subordinados e superiores }\end{array}$ & 4,02 & 3,87 \\
\hline Nível de remuneração & 3,16 & 2,70 \\
\hline $\begin{array}{l}\text { (ondiçóes no local de trabalho (instalaçóes, } \\
\text { equipamentos e instrumentos de trabalho) }\end{array}$ & 3,58 & 3,32 \\
\hline Contrato de trabalho & 4,15 & 2,77 \\
\hline $\begin{array}{c}\text { Estabilidade e segurança quanto } \\
\text { ao seu futuro profissional }\end{array}$ & 3,81 & 2,51 \\
\hline $\begin{array}{c}\text { Autonomia, ou seia, a possibilidade } \\
\text { de decidir qual a melhor maneira de realizar } \\
\text { o seu trabalho e ter iniciativa }\end{array}$ & 3,67 & 2,70 \\
\hline Envolvimento na to mada de decisões & 3,39 & 2,58 \\
\hline $\begin{array}{c}\text { Grau de interesse do trabalho, e a possibilidade } \\
\text { de utilizar as suas capacidades }\end{array}$ & 3,64 & 3,07 \\
\hline Prestígio e reconhecimento dos seus méritos & 3,46 & 2,84 \\
\hline 0 portunidades de promoção & 3,08 & 2,36 \\
\hline $\begin{array}{c}\text { Oportunidades para aprender coisas novas } \\
\text { e para a sua valorização profissional }\end{array}$ & 3,34 & 2,87 \\
\hline Tempo livre suficiente & 2,93 & 3,33 \\
\hline Poder escolher os horários/dias de trabalho & 2,98 & 2,82 \\
\hline
\end{tabular}


No entanto, por detrás das formas flexíveis de emprego podemos encontrar situações concretas muito diferenciadas. Como os resultados do nosso estudo indicam, para uns o trabalho flexível fornece oportunidades adicionais para trabalhar e obter rendimentos suplementares ou uma meIhor articulação entre o trabalho, vida pessoal e/ou o tempo de lazer. Mas, para muitos outros, essas modalidades podem traduzir-se numa redução da protecção social, em menores oportunidades de progressão na carreira, menores níveis salariais e no reduzido ou falta de acesso à formação profissional. Para uns pode se tratar de uma situação transitória, de um trampolim para uma situação melhor, para outros pode ser uma opção de acordo com o seu estilo de via. Mas também encontrámos pessoas para as quais esta situação não foi escolhida e apesar de diversas tentativas não conseguem sair dela.

A análise das entrevistas centradas nas trajectórias profissionais indica que há uma grande variedade de tipos de emprego flexível. A tipologia que se segue foi elaborada com base em entrevistas centradas nas trajectórias profissionais.

\section{- Emprego de inserção à espera de melhor}

A entrada no mercado de trabalho de Ricardo exemplifica um tipo de emprego flexível a que podemos chamar de "emprego de inserção à espera de melhor". A sua trajectória insere-se na situação 1 A) que acima designámos como "Flexibilidade precária transitória":

Ricardo de 26 anos, solteiro a viver com a mãe, trabalha desde há dois anos no call centre com o segundo contrato a termo certo (12 meses). Desempenha funções administrativas de back office e ganha 628 euros. Interrompeu o curso universitário em informática de gestão para poder trabalhar. Considera o seu trabalho pouco estimulante que não permite realização profissional nem acesso à formação profissional e sem perspectivas de carreira. Se 
sente arrependido por ter interrompido os seus estudos por reconhecer que as suas habilitações não Ihe permitem obter um melhor emprego. A relação com a empresa de trabalho temporário é muito distante e na empresa onde trabalha não passa de colaborador externo com sentimento de sem perspectivas de um dia poder fazer parte dos quadros da empresa. Considera que a situação de emprego em que se encontra "é bastante frustrante, gera insegurança, instabilidade e afecta-nos em todos os níveis". No entanto este emprego permite-Ihe adquirir experiência. O que mais deseja para a sua vida profissional é a estabilidade, gostaria de trabalhar por conta própria.

\section{- Emprego de transição para adquirir e diversificar experiência pro- fissional}

Inês, 28 anos, com um curso em Comunicação e Publicidade, actualmente trabalha numa empresa de telecomunicações. Depois de vários empregos com contratos a prazo, conseguiu emprego seguro na sua área de interesse e já mudou emprego mas dentro da esfera do emprego seguro. A sua situação alterou-se da flexibilidade precária transitória para a estabilidade profissional.

Os pais emigraram para França. A mãe, na altura, trabalhava numa fábrica de confecções, e o pai, depois, entrou nos CTT como carteiro. Ambos tinham a $4^{a}$ classe. Seguiu o curso de Comunicação Social e Publicidade e depois tirou ainda uma Pós-graduação em Marketing e Negócios Internacionais para complementar os seus estudos. Quando começou a faculdade, já estava a trabalhar. Começou a trabalhar com 18 anos dando apoio a secretariado, a tempo inteiro e com contrato a prazo [numa empresa de telecomunicações]. Depois passou para outra empresa do Grupo, no mesmo sector mas mais ligada a um projecto que Ihe deu a 
oportunidade de conhecer muita gente do "core business". Aqui permaneceu dois anos, tendo renovado entretanto contratos. Tinha funções de secretariado, mas chegou fazer telemarketing na área comercial; depois de já ter adquirido algum conhecimento profundo dessa área, passou para a assistência a clientes. TrabaIhava muitas horas. Foi, foi um período difícil porque não conseguiu chegar a tempo às aulas, não conseguiu dedicar o tempo necessário a algumas disciplinas em que tinha mais dificuldade. E entretanto mudou para outra empresa do ramo das comunicações, onde sabia que o trabalho era menos exigente. Nos primeiros tempos ainda estava a contrato a termo; mas depois passou a efectiva nos 2 últimos anos de licenciatura. Entretanto, antes de acabar o curso pretendia mudar para algo melhor. E então encontrou oportunidade de trabaIhar numa empresa do ramo das tecnologias de informação como responsável pelo Marketing de Serviços. Entrou imediatamente para os quadros. Esta experiência foi muito importante porque finalmente conseguiu trabalhar na sua área de interesse. Ficou lá cerca de 3 anos a trabalhar. Mudou há um mês atrás Ipara outra empresa das tecnologias de informação), onde está a trabalhar no domínio do Marketing.

\section{- Emprego flexível como actividade complementar}

Alberto, 33 anos, licenciado em Relações Internacionais e com um curso de pós-graduação em estudos Europeus, casado sem filhos, optou por trabalhar como trabalhador temporário a tempo inteiro para poder complementar o seu salário de professor no ensino secundário. A sua situação é complexa, numa organização encontra-se numa situação de precariedade de emprego (não do trabalho) e na outra encontra-se numa situação de estabilidade profissional, apesar de ter uma relação contratual com uma empresa de trabalho temporário. 
Alberto ganha 800 euros líquidos com contrato a termo certo na escola e 800 euros no call centre com um contrato a tempo indeterminado com uma ETT.Começou a trabalhar aos 20 anos num jornal com um contrato de prestação de serviços durante um ano e meio que terminou para prestar serviço militar. Depois leccionou em várias escolas em Lisboa e formação profissional em vários locais. Encara com naturalidade a frequente mudança de emprego. Apesar de o trabalho temporário Ihe causar alguma instabilidade, consegui adaptar-se a esta situação. No call centre começou a trabalhar com um contrato de prestação de serviços, depois passou a ter um contrato a termo de 6 meses e a seguir um contrato de 1 ano. Actualmente tem um contrato por tempo indeterminado com a empresa de trabalho temporário que praticamente desconhece. Coordena uma equipa de 10 pessoas. O seu trabalho é muito intenso e é muito prolongado. Acumulando o ensino com o trabalho no call centre trabalha 14 horas por dia (60 horas por semana), tendo dificuldades de conciliar a vida profissional e a vida privada. Valoriza o trabalho bem pago, independentemente de ser estável ou não.

\section{- Emprego flexível por opção}

Hélio 28 anos vendedor de soluções informáticas, após várias experiências profissionais voluntariamente interrompidas, optou pelo trabalho a tempo parcial para poder viver de acordo com o seu modelo de vida, no qual o trabalho é um meio e não é um fim em si mesmo. A sua situação é o emprego flexível por opção e insere-se na flexibilidade qualificante:

O Hélio tem 28 anos de idade e abandonou os estudos no final do ensino secundário, por considerar que o ensino tradicional não Ihe trazia as competências do seu interesse. É filho de pais habilitados ao nível do 
ensino superior, que não colocaram pressões sobre as escolhas do percurso de vida do filho. Fez um curso profissional de informática, cujo estágio representou o início da vida laboral. Como em todos os restantes empregos que teve, saiu por opção própria. Hoje em dia trabalha a tempo parcial por opção, em regime de teletrabalho, e gostaria de ter ainda mais flexibilidade e independência. É casado - a mulher também trabalha a tempo parcial - e tem dois filhos, enfrentando os períodos de instabilidade profissional graças a poupanças. Toca numa banda de música Jazz e as actividades de natureza social não Ihe agradam muito.

\section{- Instabilidade de emprego a longo prazo}

O percurso profissional de Carolina é mercado pela continuidade de situações precárias de emprego alternadas com desemprego. Ao todo teve 10 empregos em 7 anos. As perspectivas de melhoria da sua empregabilidade são escassas ou inexistentes devido ao seu baixo nível de escolaridade. $\mathrm{O}$ seu percurso inscreve-se na flexibilidade precária estável.

A Carolina tem 22 anos e é filha de uma cozinheira (que veio a falecer ainda na sua infância) e de um ex-Guarda Nacional Republicana, mais tarde motorista de taxi (ambos com fracas habilitações escolares), mas ficou a cargo de um tio desde os 11 anos. Estudou até ao $9^{\circ}$ ano, quando decidiu fazer voluntariamente o Serviço Militar. Acabou por desistir (por influência do namorado, a quem desagradava a falta de disponibilidade que tinha para ele) e teve de ir trabalhar porque ficou a viver sozinha, tendo exercido funções como ajudante de cozinha, sem contrato. A seguir trabalhou como operadora de caixa, e depois como repositora (em ambos os casos, com contrato a termo). Foi vendedora sem contrato, depois novamente operadora de caixa, e de novo trabalhou num restaurante. Após um período de desemprego, trabalhou com con- 
trato a termo no Jardim Zoológico, a que se seguiu novo período de desemprego e uma época em que procurou empregar-se no estrangeiro. Regressou para trabalhar como operadora de caixa (através de uma ETT), onde se encontra hoje em dia, trabalhando por turnos e com contrato a termo, que pensa não vir a ser renovado. Vive maritalmente com o namorado em casa da mãe do mesmo e não tem grandes expectativas de melhoria das suas perspectivas profissionais.

No percurso profissional de Cátia também transparece a continuidade em situações flexíveis de emprego marcadas pela precariedade ao longo dos 8 anos, apesar de se tratar de uma pessoa com um curso universitário.

Cátia, 33 anos, solteira, fez o curso de Direito. Trabalha no call centre há 3 anos, sendo actualmente supervisora. Já foi operadora e formadora no mesmo centre. Tem uma multiplicidade de experiências: trabalho de secretariado no Ministério de Educação em regime de prestação de serviços durante três anos conciliando trabalho e estudos, secretária num escritório de advogados durante um ano e meio, promotora de vendas em vários estabelecimentos comerciais, assistente de cliente de banca telefónica de um grupo bancário durante um ano. Desde 1998 trabalha no call centre onde se encontra actualmente. Queixa-se da ansiedade, frustração, falta de motivação, preocupação diária e constante com o futuro, para além do rendimento baixo. Caracteriza a sua situação com "a falta de perspectivas de futuro, impotência para traçar projectos, endividamento, insegurança e instabilidade". Trabalha a tempo inteiro (7 horas diárias) como vinculada a uma empresa de trabaIho temporária com um contrato a termo de 12 meses pela terceira vez. Ganha 887 euros. Descreve o seu trabalho com intenso, stressante e absorvente. Devido à sua situação de emprego dificilmente poderá obter cré- 
dito bancário para comprar habitação. ${ }^{15}$ Receia o futuro: tem medo de perder a casa, a sua independência e a entrar numa ruptura económica e psíquica. O que mais deseja, é a estabilidade.

\section{Conclusões}

As formas flexíveis de emprego - associadas, sobretudo à flexibilidade quantitativa - são ainda minoritárias se as compararmos com a proporção de empregos com contratos de duração indeterminada. Contudo, actualmente, eles constituem uma via de acesso normal para a integração no mercado de trabalho. Uma parte substancial dos trabalhadores com emprego flexível encontra-se nesta situação não por opção, mas porque não conseguiu encontrar um emprego estável.

São, sobretudo, mulheres, jovens, os grupos etários mais elevados, os pouco qualificados e os menos escolarizados que ficam mais abrangidos por formas flexíveis de emprego geradoras de uma empregabilidade frágil. A reprodução das situações de emprego significa que a sua mobilidade tende a limitar-se à esfera do trabalho pouco qualificante, tanto dentro da mesma empresa como na mudança de uma empresa para outra, comportando características que perpetuam a fragilidade no mercado de trabalho, nomeadamente a falta de possibilidades de formação e de promoção profissional. Essa fragilidade aumenta ainda mais quando um emprego precário alterna com períodos de desemprego. A situação de desemprego, sobretudo o da longa duração, tem como consequência a desaprendizagem e a perda de qualificações. Por sua vez, a permanência numa situação de precariedade não permite melhorar a empregabilidade das pessoas. 
A situação no emprego, num contexto onde o bom emprego tende a tornar-se num bem escasso, tem consequências individuais e sociais múltiplas, não apenas em termos de nível de consumo e qualidade de vida, perspectivas de vida futuras, segurança social e acesso a actividades colectivas, mas igualmente em termos de acção e intervenção individual e colectiva, nomeadamente para a defesa de interesses.

A tendência para a reprodução das situações de emprego refuta as ilusões ligadas à grande mobilidade profissional. As situações de emprego muito diferenciadas implicam não apenas níveis de satisfação muito diferenciadas, mas também oportunidades muito diferenciadas para o aumento das qualificações, aquisição de novas competências e, por conseguinte, para a melhoria da empregabilidade.

Parece existir um desencontro entre as expectativas dos trabalhadores e as políticas de emprego. Os estudos indicam que as expectativas da maior parte dos trabalhadores incidem sobre a estabilidade do emprego, mais os meios políticos e empresariais tentam impor as formas flexíveis (sobretudo precárias).

As formas flexíveis de emprego são ambíguas, e por conseguinte, podem ter implicações diferenciadas segundo o tipo de trajectórias profissionais dos trabalhadores. Como os resultados da nossa investigação indicam, para uns o trabalho flexível pode ser uma opção para outros é uma imposição. Para uns pode se tratar de uma situação transitória com o objectivo de passar para uma situação melhor. Porém, para muitos outros, trata-se de uma armadilha que amarra os trabalhadores a uma espiral de precariedade e à falta de perspectives profissionais. 


\section{Referências:}

ATKINSON, John. La flexibilité de l'emplois sur le marché internes et extrenes de travail. In: DAHRENDORF, R.; KOHLER, E.; PIOTET, F. Nouvelles formes de travail et activité, Dublin: Fondation Européenne pour l'Amélioration des Conditions de Vie et de Travail, 1987. pp. 3-48.

BREWSTER, Chris; Mayne, Lesley; Tregaskis Olga M. Flexible working in Europe. Journal of World Busines, Summer, v.32, 1997.

BRIDGES, William. Jobshift. Addison Wesley Publ., 1994.

CABRAL, Manuel Villaverde (coord.), Atitudes Sociais dos Portugueses (Bases de dados) 1997. Orientações perante o trabalho. Lisboa: ICS, 1998.

CASTEL, Robert, Les métamorphoses de la question sociale. Une chronique du salariat, Paris: Fayard, 1995.

CASTILLO, Juan José. Em busca do trabalho perdido (e de uma sociologia capaz de o encontrar...). In: KOVÁCS, Ilona; CASTILLO, Juan José, Novos modelos de produção: Trabalho e pessoas. Oeiras: Celta Editora, 1998.

COMISSÃO EUROPEIA. New formes of work and activity. Dublin: European Foundation for the Improuvement of Living and Working Conditions, 1998.

DE GRIP, Andries; HOEVENBERG, Jeroen e WILLEMS, Ed. L'emploi atipique dans I'Union europèenne, Revue Internationelle de Travail, v. 136, no1, pp. 55-78. 1997.

EUROSTAT, Labour Force Survey. 2001, 2002.

FELSTEAD, Alan and JEWSON, Nick (eds). Global Trends in Flexible Work. London: Macmillan Pres Ltd, 1999.

FREIRE, João (coord.). Atitudes face ao Emprego, Trabalho e Tempo Livre. Lisboa: Observatório do Emprego e da Formação Profissional, 2000.

FREIRE, João. O Trabalho Independente em Portugal. Lisboa: CIES/ISCTE, 1995. 
GORZ, André. Misères du présent. Richesses du possible. Paris: Édition Galiée, 1997.

HANDY, Charles. The Future of Work. Oxford: Blackwell, 1984.

HASSAN, Abrar. Desenvolvimento do mercado de trabalho e política de educação e formação. Formação Profissional, Berlim: CEDFOP, 2, 1994.

KOVÁCS, Ilona. Os jovens e a renovação da pesca: expectativas e aspirações em relação aos trabalho e à vida profissional. In: Pescas e Pescadores (ed. em colaboração com A. Brandão Moniz e M. Mira Godinho), Oeiras: Celta ed. 2000. pp.4574.

KOVÁCS, Ilona. As Metamorfoses do Emprego. Oeiras: Celta Editora, 2002.

KOVÁCS, Ilona, CASTILLO, Juan José. Novos modelos de produção: Trabalho e pessoas. Oeiras: Celta Editora, 1998.

KOVÁCS, Ilona. Reestruturação Empresarial e emprego. Perspectiva, Florianópolis, v. 21, n. 2, pp. 467-494, jul./dez. 2003.

KOVÁCS, Ilona. Trabajo, cualificaciones y aprendizaje a lo largo de la vida. In: Sociologia del Trabajo, Madrid, n. 34, pp.3-25, Otoño. 1998.

MONIZ, A. Brandão e KOVÁCS, Ilona. Evolução das Qualificações e das Estruturas de Formação. Lisboa: IEFP, 1997.

OCDE. Employment Outlook. Paris: OCDE, 2000.

OCDE. Perspectives de l'emploi. Paris, 1999.

PRESIDÊNCIA DA REPÚBLICA. A Reforma do Pacto Social. Lisboa: Imprensa Nacional - Casa da Moeda, 1999.

RIFKIN, Jeremy. The End of Work: The Decline of the global Labor force and the New Post-Market Era. New York: J. P. Tacher; G.P. Putnam's Sons, 1995.

ROSA Teresa (Coord.) et al.. Trabalho precário - perspectivas de superação. Lisboa: CIES, OEFP, Relatório Final, 2000. 
SANTANA Vera e CENTENO, L. G. (Coord.). Formas de Trabalho: Trabalho Temporário; Subcontratação, CIDEC, OEFP. Relatório Final, 2000.

VAZ, Isabel Faria. As formas atípicas de emprego e a flexibilidade do mercado de trabalho. Colecção Estudos. Lisboa: Ministério da Qualificação e Emprego, 1997.

VISSER, J, HEMERICJK, A.C. A “Dutch Miracle" Job Growth, Welfare Reform and Corporatism in the Netherlands. Amstardam: Amsterdam University Press, 1997.

Recebido: 15/03/2004

Aceite final: 17/06/2004 


\section{Resumo}

Este artigo, baseado nalguns dos resultados de um projecto de investigação em curso, tem por objectivo analisar a difusão do emprego flexível em Portugal e mostrar a sua diversidade.

A difusão de formas flexíveis de emprego insere-se nos processos de reestruturação produtiva e flexibilização do mercado de trabalho no contexto da intensificação da concorrência na economia global.

Recorrendo a dados estatísticos procede-se a uma análise da difusão e da evolução de algumas das formas mais relevantes de emprego flexível em Portugal, tais como o trabalho com contratos de duração determinada, o trabalho temporário, o trabalho independente e o trabalho a tempo parcial. Os trabalhadores com emprego flexível têm níveis de satisfação bastante inferiores aos dos trabalhadores com emprego estável. No entanto, o emprego flexível não abrange situações de emprego homogéneas, mas situações muito diversificadas que são apresentadas através de uma tipologia de situações de emprego flexível e uma tipologia de trajectórias profissionais.

Palavras-chave: emprego, flexibilidade, Portugal, tipos de emprego flexível. 